ing. Mannitol was retained during the forced diuresis, and there appeared to be a net movement of water from the intracellular to the extracellular space.

$\mathrm{Had}$ the urine $\mathrm{pH}$ values during the frusemide diuresis and the mannitol diuresis been better matched the differences in $\mathrm{U} / \mathrm{P}$ for phenobarbitone (Table III) would have been reduced further. Bloomer (1966) showed that when the urine $p H$ was increased from 7.5 to 8 the ratio $U / P$ for phenobarbitone was increased twofold to threefold. Similar considerations do not affect pentobarbitone, amylobarbitone, quinalbarbitone, and butobarbitone, for these drugs have $p \mathrm{~K}_{a}$ values of the same order as the upper limit of urine $\mathrm{pH}$ in man (Krahl, 1940). $\mathbf{U} / \mathbf{P}$ for pentobarbitone and quinalbarbitone was not significantly increased by making the urine alkaline (Bloomer, 1966).

\section{Conclusions}

No worth-while benefit stems from the use of forced diuresis in the treatment of severe intoxication with pentobarbitone, amylobarbitone, and quinalbarbitone.

It is reasonable to use forced diuresis in severe poisoning by butobarbitone or phenobarbitone, since the unchanged hypnotic is a prominent component of the barbiturate derivatives excreted in the urine. For this purpose frusemide is not inferior to mannitol.

\section{Summary}

Eight patients with acute barbiturate poisoning have each been treated by periods of forced diuresis with mannitol and with frusemide.

The urinary excretion of unchanged barbiturate hypnotic has been determined by gas-liquid chromatography and the excretion of total barbituric acid derivatives by spectrophotometry.

The unchanged hypnotic represented only $6-14 \%$ of the total urinary barbituric acid derivatives excreted by patients poisoned with pentobarbitone, amylobarbitone, or amylobarbitone plus quinalbarbitone. The excretion of unchanged hypnotic did not exceed $100 \mathrm{mg}$. in nine hours and probably had no therapeutic significance.

The proportion of the total urinary barbituric acid derivatives excreted as unchanged phenobarbitone or butobarbitone varied from 38 to $81 \%$.

Mannitol appeared to have no important practical advantages over frusemide as a means of inducing diuresis.

It is concluded that forced diuresis with frusemide may reasonably be used in the treatment of severe poisoning with butobarbitone or phenobarbitone but that there is no indication for forced diuresis in poisoning due to pentobarbitone, amylobarbitone, or quinalbarbitone.

The patients were admitted to the care of Professor D. A. K. Black in the Manchester Royal Infirmary. Sister Officer and her staff in the respiratory care unit were responsible for the determinations of urinary flow rate and for the detailed labelling of urine samples. Mrs. M. Rodgers gave able technical assistance. The following firms gave chromatographic standards of drugs: Bayer Products Co., British Drug Houses Ltd., Eli Lilly \& Co. Ltd., Geigy (U.K.) Ltd., May and Baker Ltd., and A. Wander Ltd.

The investigation was supported by the Research Grants Committee of the United Manchester Hospitals.

\section{REFERENCES}

Bloomer, H. A. (1965). New Engl. F. Med., 272, 1309.

Bloomer, H. A. (1966) F. Lab. clin. Med., 67, 898. Bloomer, H. A. (1967). Lancet, 2, 986.

Brochmann-Hanssen, E., and Svendsen, A. B. (1962). F. pharm. Sci., $51,318$.

Cochin, J., and Daly, J. W. (1963). F. Pharmacol. exp. Ther., 139, 154. Goldbaum, L. R. (1952). Analyt. Chem., 24, 1604.

Goldstein, A. (1964). Biostatistics. London.

Goldstein, A. (1964). Biostatistics. London. 688.

Irrgang, K. (1965). Arzneimittel-Forsch., 15, 688.

Linton, A. L., Luke, R. G., and Briggs, J. D. (1967). Lancet, 2, 377.

McMartin, C., and Street, H. V. (1966). F. Chromat., 22, 274.

Moss, M. S. (1965). Proc. Ass. clin. Biochem., 3, 218.

Varley, H. (1967). Practical Clinical Biochemistry, 4th ed. London.

\title{
Horseshoe Kidney, Renal Arterial Anomalies, and Hypertension: a Study of One Family
}

\author{
P. W. ROBERTSON,* M.D., F.R.C.P.
}

Brit. med. F., 1968, 2, 793-797

Horseshoe kidney is a well-recognized congenital malformation. The frequency with which it may occur has been variously estimated at between 1 in 400 of the general population (Glenn, 1959) and 1 in 1,000 (Walters and Priestley, 1932). Bell (1950) noted its occurrence in 119 necropsies out of a series of 59,064, giving an incidence of 1 in 497. Males are said to be rather more often affected than females.

Horseshoe kidney occurs from the fusion of the renal blastomas at a very early stage of foetal development, variously given as fourth to eighth week (Glenn) and eighth to tenth week (Bell). At this stage the lower poles of the primitive renal structures are in close proximity (it is very rare for the anomaly to cause fusion of the upper poles, producing an inverted horseshoe, but this can occur ; so can total fusion, giving a cake or plate kidney). This early maldevelopment carries with it a persistence of the more primitive arterial supply arising from iliac arteries, lower aorta, or, very rarely, inferior mesenteric artery.

* Consultant Physician, East Birmingham Hospital, Birmingham 9.
Association of multiple renal arteries with horseshoe kidney does not seem to be particularly well known, though a careful examination of the text and the illustrations of many past papers does indicate the presence of multiple renal arteries. Thus Glenn's paper referred to eight patients who had been explored surgically, and specifically noted the presence of accessory renal arteries in seven of these.

In a recent study (Robertson et al., 1967) attention was drawn to the invariable finding of multiple and anomalous renal arteries in horseshoe kidney investigated by angiography. It was also noted that, in some instances at least, various members of the same family had multiple renal arteries, and it was suggested that in some families with a strong family history of "essential hypertension" the inherited factor might be renal dysplasia.

We have often noticed the similarity in renal shape between many of the kidneys with multiple renal arteries in our hypertensive patients-the rather sausage-shaped structures-and the shape of the vertical limbs of the horseshoe. Variations in horseshoe shape and in the shape of multiple-artery kidneys have suggested that all these might be similar malformations varying 
only in degree. It has therefore been of considerable interest to study a family in which these variations could be shown in many members and in differing generations.

The findings are now presented from the investigation of this large family, many of whom were hypertensive: in all but one of those in whom angiography was possible renal arterial anomalies were seen, and in one patient a full horseshoe kidney was demonstrated.

\section{Materials and Methods}

This family came to our attention from the initial investigation of one member-a 33-year-old married woman (XY III 7) referred for investigation of hypertension noted on routine examination in a surgical ward. During the course of the history it emerged that she was one of nine children, most of whom were known to be hypertensive; and that her mother was one of 15 children, many of whom were known to be hypertensive. Clinical information was obtained about three generations of this family, and in some instances radiological studies were completed. Some rather indirect information was obtained about a fourth generation-the grandfather of our original patient.
Renal angiography has been a feature of our routine investigations of hypertension for some years. Some aspects of this have been described and discussed elsewhere (Robertson et al., 1962, 1967). All angiograms were performed by the retrograde femoral route and Seldinger technique. A number of the members of this family agreed to angiography after a full explanation had been given of what this procedure involved. Some underwent full investigation; others were personally interviewed and examined even if not investigated. In a few instances information could be obtained only by correspondence with relatives, but where possible their family practitioner was contacted and clinical details were obtained. Some information on about 100 members of this family was gathered directly or indirectly.

\section{Results}

Interrogation of various members of the family produced the family tree shown in Fig. 1. Those known to be hypertensive are marked with cross-hatching and those who have been angiographed (a total of eight patients) are shown with an (A).

The findings from clinical and radiological assessment of some individual members of this family are described.

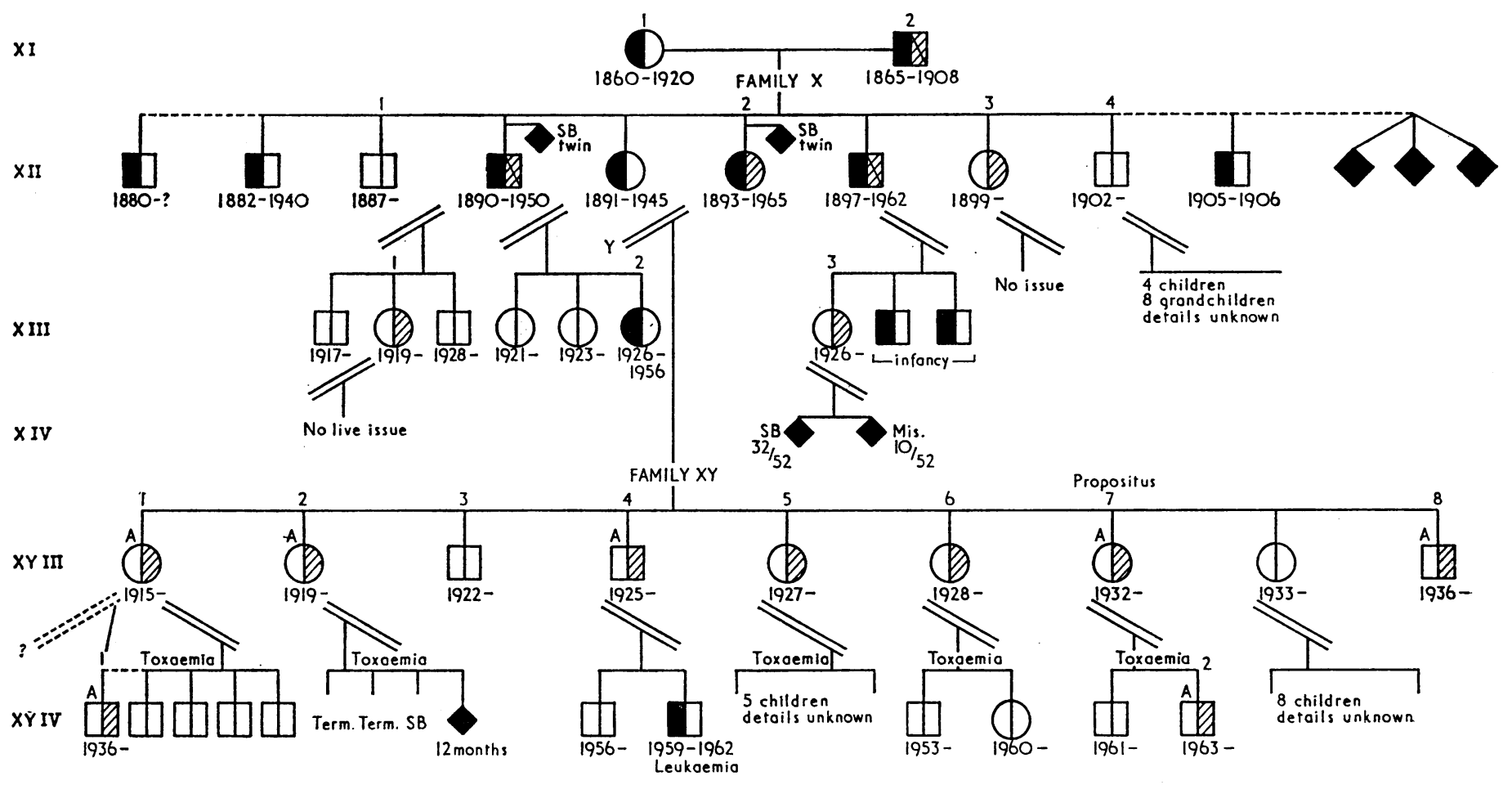

$\mathbf{Y}$

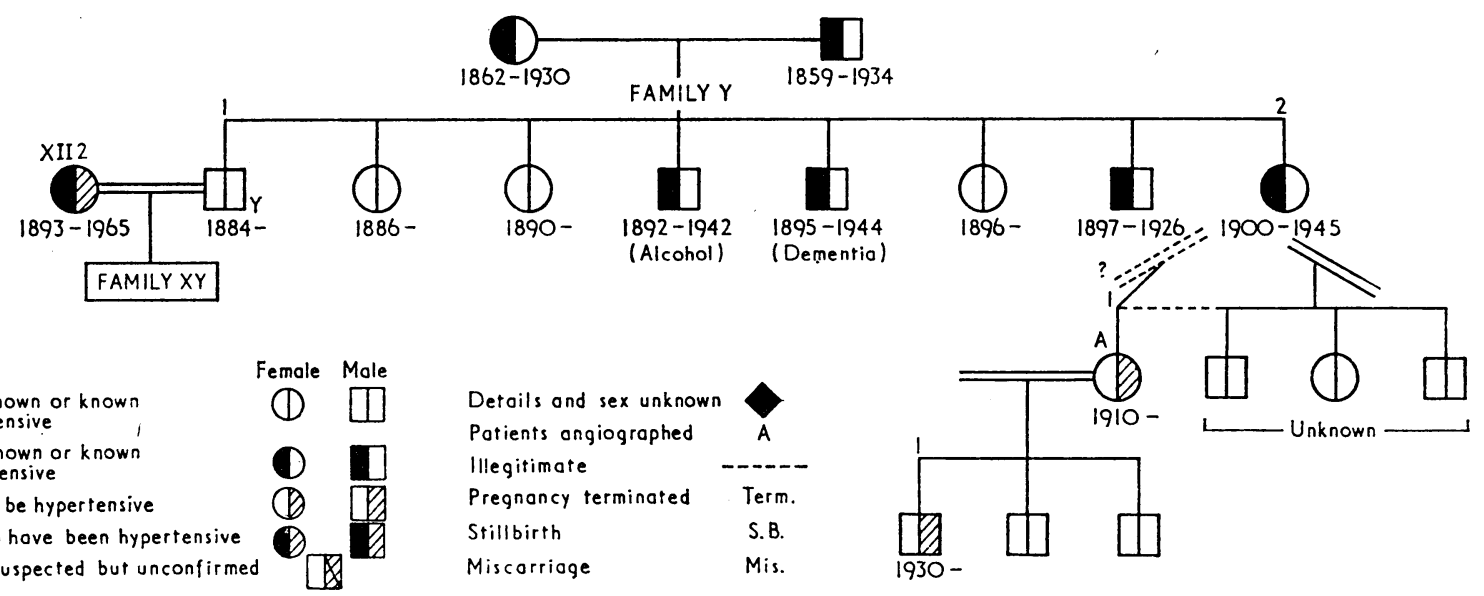

FIG. 1.-Genealogical trees of Family X, Family XY, and Family Y. 


\section{Cáse XY III 7}

The patient was a woman aged 33 . Hypertension was found at routine examination in a surgical ward during an admission for fibroadenoma of the breast. There was a history of toxaemia with her pregnancies $6 \frac{1}{2}$ and $3 \frac{1}{2}$ years previously. The patient was symptomless, with blood-pressure levels about $220 / 130 \mathrm{~mm}$. $\mathrm{Hg}$ untreated. Routine investigations showed normal renal function, but slight proteinuria. No biochemical abnormalities were found, but radiology showed a horseshoe kidney. Renal angiography confirmed the renal anomaly and demonstrated a multiple renal arterial pattern (see Fig. 2).

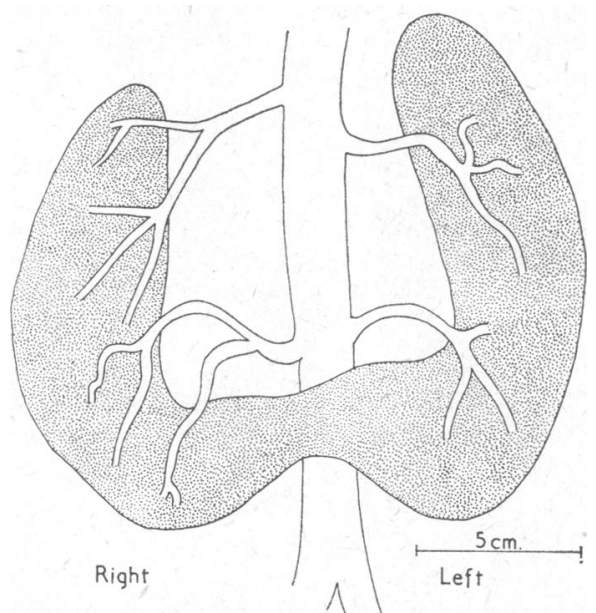

FIG. 2.- Scale drawing from the renal angiogram of the proposita, Case XY III 7. There are four the proping four main renal arteries supplying a full horseshoe kidney. The shape of the vertical limbs of this kidney is strongly reminiscent of the rather sausage-shaped renal outline so often seen in others with separate kidneys and a multiple arterial supply.

Comment.-This patient gave the original introduction to the family under study. Her symptomless hypertension was sustained at a high level, and she has been treated medically. One of her children was subsequently referred to us; he has been investigated, and is included in this series (XY IV 2).

\section{Case XY III 4}

This man, aged 42, a brother of the proposita (XY III 7), agreed to be examined. There was no medical history of note apart from a recent fractured leg in a mining accident. The blood pressure was mildly elevated at $170 / 100 \mathrm{~mm}$. Hg. There was no history of renal or urinary troubles. A renal angiogram showed renal arterial anomalies, an early division of the right main renal artery supplying a rather sausage-shaped right kidney; and on the left

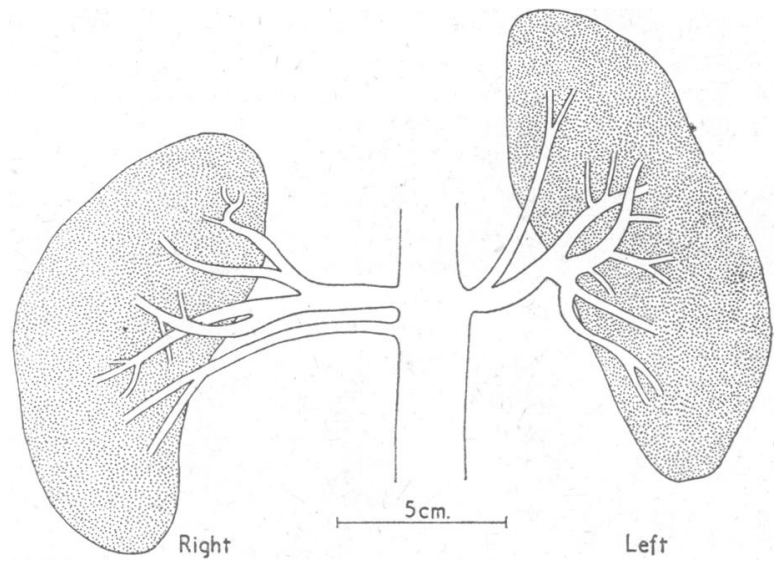

FIG. 3.-Scale drawing from the angiogram of Case XY III 8. This patient is the youngest brother of XY III 7 (Fig. 2). There are two separate renal arteries on the right; a very early division of the main renal artery on the left supplies the upper pole. there were two quite separate renal arteries, of which one again divided early.

Comment.-There was symptomless hypertension of mild degree requiring no treatment. The renal arterial pattern was of the type commonly seen in "essential hypertension."

\section{Case XY III 8}

The youngest brother (aged 30) of the proposita was symptomless and had never been ill. He worked as a miner. He had had routine examinations in the past, and was told that his blood pressure was " a bit raised." At this hospital the level was 150/100 mm. Hg. There was no proteinuria. He agreed to undergo renal angiography, which showed a double arterial supply to the right kidney and an early division of the left renal artery (Fig. 3).

Comment.-This was the youngest member of the same generation as the proposita and not yet at an age at which "essential hypertension" is allegedly most prevalent. None the less, he had above-average levels, and is likely to become more hypertensive in later years.

\section{Case XY III 1}

The eldest sister (aged 52) of the proposita, married with five children (the firstborn having a different father). She claimed to be in good health and supplemented her family's income by heavy farm work. Her blood pressure was about $250 / 140 \mathrm{~mm}$. Hg. She knew that she had had hypertension since the pregnancies, with all of which "blood pressure and kidney trouble" were associated, requiring a caesarean section for her first child (XY IV 1).

She was fully investigated in hospital, findings being largely negative: normal intravenous pyelogram and renal function, no proteinuria, normal biochemistry. Renal angiography, however, showed an early division of the right renal artery and multiple arteries to the left kidney.

Comment. - Hypertension found during pregnancy, especially if associated with proteinuria, is so often labelled "toxaemia" and yet is not "true toxaemia." There is no evidence that this patient was ever normotensive from the time of her first antenatal examination until the present day. Her hypertension was of considerable degree, and it was thought desirable to advise medical treatment. It is of interest that her eldest child (XY IV 1) is already hypertensive.

\section{Case XY III 2}

This married woman, aged 48, a sister of the proposita, was known to have had severe hypertension for many years. Four years previously she had been treated elsewhere for "malignant hypertension." There was no history of renal illness in the past. She had no living children, but there had been four pregnancies: "toxaemia" occurred with all-two were terminated, one ended in miscarriage, and one resulted in the birth of a live infant, which later died from meningitis. She had been on hypotensive drugs for years.

Investigations here showed mild proteinuria and increased white cell excretion in the urine, which was sterile. Blood urea was normal. The intravenous pyelogram and renal angiogram were normal in all respects.

Comment.-This is the only member of the family who has been shown to have a normal renal arterial pattern on angiography. None the less, she has long-standing severe hypertension with continuing proteinuria and raised Addis counts. The exact significance of the history of toxaemia is not clear in this patient. In this instance there was no evidence of gross dysplasia ; renal biopsy was not undertaken.

\section{Case XY IP 1}

This man, aged 30, was the eldest child of XY III 1 and nephew of the proposita. He worked as a bulldozer driver, and was one of 
two members of this generation investigated by angiography. $\mathrm{He}$ was found to have hypertension some years before, when treated for a back injury. He had been investigated elsewhere, though without renal radiology. Symptomless hypertension was confirmed at this hospital, with levels up to $175 / 120 \mathrm{~mm}$. $\mathrm{Hg}$, though more usually $150 / 110 \mathrm{~mm}$. $\mathrm{Hg}$. He agreed to renal radiology without detailed investigation, and was shown to have a rather long thin left kidney with a double arterial supply. The right side appeared normal (Fig. 4).

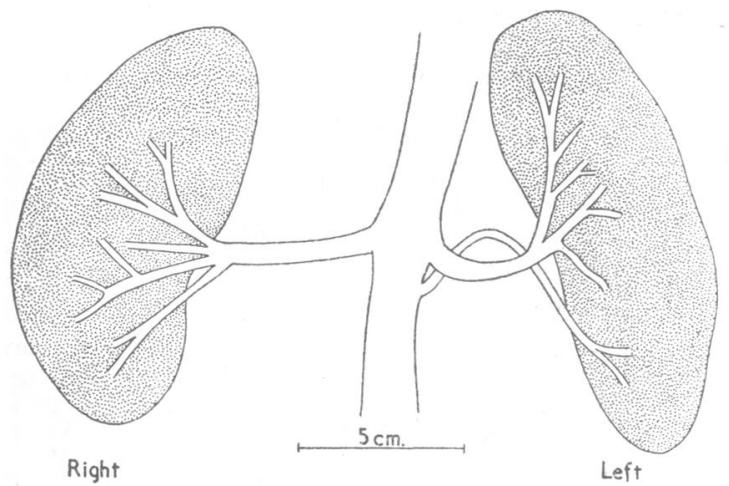

FIG. 4.- Scale drawing from the angiogram of Case XY IV 1. This patient is the nephew of patients in Figs. 2 and 3 . There is a double arterial supply to a rather sausage-shaped left kidney.

Comment.-This man was known to have had hypertension from the age of 25 years, and it was assumed by others to be " essential hypertension." The renal arterial pattern showed the same type of renal anomaly found in other members of this family.

\section{Case XY IV 2}

This boy, aged $3 \frac{1}{2}$, the second son of the proposita (with a horseshoe kidney), was referred to us because of urinary symptoms -diurnal and nocturnal frequency and incontinence. He was otherwise well, and physical examination was negative apart from a slightly raised blood-pressure reading for his age $(115 / 80 \mathrm{~mm}$. $\mathrm{Hg}$, by use of a child's sphygmomanometer cuff). An intravenous pyelogram was normal, but a renal angiogram showed a double arterial supply to the left kidney, which was of a slightly elongated shape. The right kidney had normal angiographic appearances (Fig. 5).

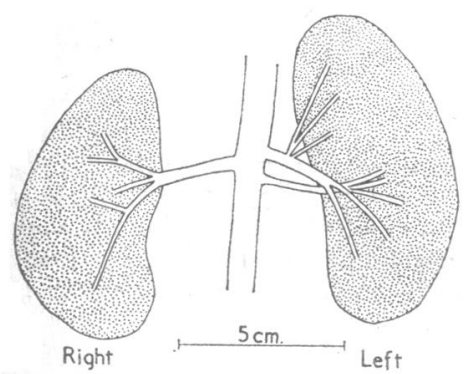
Fig. 5.- Scale drawing from the This child, aged $3 \frac{1}{2}$, is the son of Case XY III 7 (Fig. 2). There are two renal arteries supplying the left kidney, and some unusual branches from the larger of these supply the upper pole of a kidney already rather elongated.

Haemoglobin and blood urea were normal. Urine cultures repeatedly proved positive, with a proteus organism predominating. This was assumed to be contributing to the persistent complaint, and appropriate treatment was initiated.

Comment.-This child shows the same renovascular pattern as many of his relatives in the preceding generation. One relative of the same generation (his cousin XY IV 1) also shows this anomaly. The mild renal dysplasia may predispose to renal infection.

Notes on other members of this family are given in the Appendix.

\section{Discussion}

The family concerned proved to be an interesting social as well as clinical study. The district from which they originated was a small and old coal-rnining and industrial area in a largely rural community. The mines had long since closed, but many families lived in miners' cottages in a rather isolated but close community. Members of the main family were visited at home, sometimes more than once, in an effort to obtain an idea of their background and upbringing.

Our original patient (XY III 7) was a pleasant woman who remained the most useful guide to the complicated affairs of this family. The size of the families has proved useful for this type of investigation-in general they seem to have been prolific, though several marriages failed to produce live children, with unconfirmed accounts of infant deaths from "kidney trouble."

Illegitimacy has occurred in various generations, but one patient known to be illegitimate still inherited his mother's renal artery pattern. It does not seem impossible that some of the illegitimate pregnancies were the result of closely consanguineous relationships.

The father of the proposita (Y II 1) was a rough and looseliving alcoholic miner, several of whose siblings died from the effects of alcohol or mental illness, but none it is thought from hypertension. He himself remains normotensive, in good health at 82 years of age, a fact which some of the family consider something of an injustice.

The behaviour of the maternal grandmother of the proposita (X I 1) was unconventional, and it is now known that several of her pregnancies were illegitimate (from various associations before, during, and after her marriage to X I 2), which has complicated the interpretation of the inheritance of the hypertension.

In some instances only the fireside recollections of elderly survivors of the family are available for purposes of record. These, though picturesque and pithy, hardly constitute scientific evidence. It must be remembered, however, that nothing much more reliable would have been forthcoming even if contemporary medical records were available, since the use of a sphygmomanometer has become general only in the past 40 to 50 years.

For those relatives who lived before that time one is entitled to consider Bright's disease, heart disease, and strokes as disorders of probable significance in the context of hypertension (Platt, 1947).

The likelihood of finding a positive family history for hypertension in any patient with essential hypertension has long been stressed (Platt, 1947), and the hypertension under investigation in this family would normally be regarded as "essential," except perhaps for that of the patient with the horseshoe kidney. In earlier papers we have shown that a high proportion of patients with essential hypertension have renal arterial anomalies ; it was suggested that renal dysplasia was in some way the cause of the hypertension, and that it was this condition which was the inheritable factor in many cases of hypertension. In the present paper it has been possible to take one large family with a strong family history of hypertension and demonstrate in several generations similar renal arterial anomalies.

The age at which patients become hypertensive with renal dysplasia can vary greatly, and it was our experience in another series that our hypertensive patients presented much the same age range as would be expected in normal clinical practice. However, we drew attention to the difficulty of deciding an age of onset, as opposed to an age of discovery-and in this family that may be well seen. Most of the family have no symptoms and would not normally be aware of the hypertension or renal anomaly. Many have lived into their 70 s even though markedly hypertensive. It does seem certain that with a more conventional approach most of these patients would be regarded as having "essential hypertension," and only by full assessment with angiography does their underlying renal dysplasia become evident.

The family under study appears to have derived its hypertension from the $\mathrm{X}$ side of the family tree. Since some of the sibs of the proposita have children who are developing hyper- 
tension, there is clear evidence of hypertension in three successive generations and presumptive evidence of a fourth generation (in X I 2). The arterial anomaly does seem inheritable as a dominant factor with a very high degree of penetrance; there is no evidence of any sex-linked factor. It was of interest that a patient who was investigated for severe hypertension (Y III 1) turned out to be an illegitimate daughter of the $Y$ side of the family, in which hypertension does not seem to be prevalent (her mother was a sister of Y II 1 ; her father could not be determined). This patient was shown to have a normal renal arterial pattern. However, her eldest son is also known to have hypertension, though the renal artery pattern is unknown.

"Toxaemia" is a diagnosis which has appeared often in the history of this family. At least 18 pregnancies among the sibs of the propositus had toxaemic courses, and several cousins had "toxaemia," or lost their pregnancies, or were advised to have no children. We have mentioned the association of "toxaemia" with renal artery anomalies in a previous paper: it is clear that since many women with arterial anomalies may conceive (and relative infertility does not seem to be a feature of such patients) labile or latent hypertension may then become more evident. Alternatively, it may be that at a routine antenatal examination blood-pressure levels are first recorded and pre-existing hypertension is wrongly assumed to be related to the pregnancy. We have many times in the past established in individual patients the association of renal dysplasia with "toxaemia." In the family under study this has been particularly evident.

\section{Summary}

A patient with symptomless hypertension was shown to have a horseshoe kidney with multiple renal arteries. The history of her family has been studied, and details have been obtained of many members covering four generations. An exceedingly strong family history of hypertension, and in some instances "toxaemia of pregnancy," has been shown to be associated with renal arterial anomalies: renal dysplasia has been either obvious (in the patient with horseshoe kidney) or inferred by arterial anomalies with or without abnormal renal shape.

The study of this family appears to provide additional evidence to support the view that renal arterial anomalies, renal dysplasia, and hypertension are associated and can be inherited.

\section{APPENDIX.-Notes on some other members of the family}

Case XI1.-This woman lived from about 1860 to 1920 . She was the mother of some 15 children, though X I 2 was not the father of them all. She remarried after the death of her first husband, but had no further pregnancies from her second marriage. Died from malignant disease.

Case X I 2.-This man lived from about 1865 to 1908 . He was great-grandfather of the youngest generation in this study. Known to have died from dropsy. Worked in a forge. His wife had 15 children, including three sets of twins, though he was not the father of them all. Several known to have had hypertension or renal disorder, though only three survive.

Case X II 1.-Man aged 80, the eldest living child of X I 1. Said to be in good health. Blood pressure unknown. Worked as a miner for many years in another part of the country.

Case X II 2.-This woman (1893-1965) had severe hypertension for years before death. Figures of $300 / 140 \mathrm{~mm}$. $\mathrm{Hg}$ had been recorded by her general practitioner. Never investigated. She was one of twins, the other dying at birth. She was the mother of nine children, at least seven of whom are known to have had hypertension. At least 17 of the pregnancies occurring in her female children were associated with "toxaemia."

Case X II 3.-This woman, aged 68, was visited at home. The principal source of information for this generation. Sister of X II 1-that is, aunt to the majority of patients investigated.
Known to have had some hypertension for many years, but never investigated. Received hypotensive drugs, but did not take them. Kept bottles of "pretty-coloured tablets" on the mantelshelf. Never able to conceive despite two marriages.

Case X II 4.-Man aged 65 who moved away from the district many years ago. He wrote to say that he has four children and eight grandchildren, who were all well, and he knew of no hypertension.

Case X III 1.-This woman aged 48 was a cousin of the main group investigated. Her general practitioner wrote to say her mild hypertension $(170 / 100 \mathrm{~mm}$. $\mathrm{Hg})$ had been noted but not investigated. Apparently unable to conceive. Her father died at 60 years with aortic aneurysm and hypertension.

Case X III 2.-This woman died at 30 years after septic abortion. Full medical details unknown. She was unmarried: the father was said to be XY III 3, who is known to be normotensive.

Case X III 3.-Woman aged 40. We were informed by her general practitioner that she had had toxaemia of pregnancy with each of her two pregnancies, both of which ended in loss of the infant. Her father died at 65 , and was thought to have had hypertension. She had hypertension and proteinuria during the pregnancies, and subsequently persisted with minimal hypertension (latest figure recorded $165 / 90 \mathrm{~mm} . \mathrm{Hg}$ ). She was herself one of three children, the other two dying in infancy.

Case XY III 3.-Unmarried brother (aged 46) of the propositus. In good health, working as a coal miner. Blood pressure 130/ $80 \mathrm{~mm}$. $\mathrm{Hg}$.

Case XY III 5.- This patient, a woman aged 39, wrote to say she had hypertension and had had "toxaemia" with all her five pregnancies. She moved away from the district many years ago, and at the time of writing was attending her local hospital.

Case XY III 6.-A woman aged 37 moved away from the district, and wrote to say she had had hypertension and "toxaemia" with both pregnancies 14 and 6 years previously. She believed she still had hypertension.

Case Y II 1.-This man, aged 83, was visited at home. In good health. Blood pressure $155 / 75 \mathrm{~mm}$. Hg. The father of the majority of the patients investigated. Worked as a coal miner for most of his working life. Father of nine children. He was himself one of eight children, of whom four are alive, aged between 70 and 85 . Of the others one died in a mental hospital at 49, another from the effects of alcohol at 50, and one from rheumatic fever at 29 . One girl left home after an illegitimate pregnancy, and is believed to have died at about 45 years of age from an unknown cause. No member of his generation was known to have hypertension, nor were his parents thought to be hypertensive.

Case Y II 2.-This woman lived from about 1900 to 1945 . She was the youngest sister of Y II 1 . Cause of death unknown. Left home after an illegitimate pregnancy resulting in the birth of $Y$ III 1. Father of child unknown.

Case Y III 1.-Daughter (aged 51) of Y II 2, but brought up by grandparents and never knew her parents. Found to have hypertension $(220 / 140 \mathrm{~mm} . \mathrm{Hg})$ and investigated in this study. Shown to have normal renal arterial pattern. Some evidence of chronic urinary infection. This patient is the first known hypertensive in the $\mathrm{Y}$ family, and it seems likely that this was either "secondary" (perhaps unlikely in view of the hypertension in her son) or acquired from an unknown father.

Case Y IV 1.-Eldest son (aged 37) of Y III 1 and known to have hypertension. His practitioner wrote from a distant town to say that investigations at a local hospital had shown no cause for this, though no angiogram had been done. His brothers are said to be normotensive. If his mother had " secondary" hypertension then he may have acquired his hypertension from his father, or might coincidentally also have secondary hypertension (though investigations, such as they were, proved unhelpful).

\section{REFERENCES}

Bell, E. T. (1950). In Renal Diseases, 2nd ed., p. 79. London.

Glenn, J. F. (1959). New Engl. F. Med., 261, 684.

Platt, R. (1947). Quart. F. Med., 16, 111.

Robertson, P. W, Klidjian, A., Hull, D. H., Hilton, D. D., and Dysan, M. L. (1962). Lancet, 2,567.

Robertson, P. W., Hull, D. H., Klidjian, A., and Dyson, M. L. (1967). Amer. Heart \%., 73, 296.

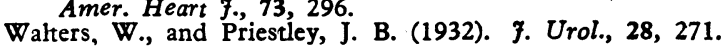

